for a variety of materials an approximately linear relationship is found to exist between the moisture content and the attenuation of the beam.

The provision of concrete shields for nuclear reactors presents a new and complex problem in the field of materials and structures which is being studied by the Building Research Station in collaboration with the U.K. Atomic Energy Authority. Instruments are being installed in the shield of the fourth reactor now under construction at Calder Hall for the measurement of strain, temperature, joint displacement and moisture. It is expocted that the observations obtained will provide valuable data for future designs.

In the field of lighting, fundamental work is in progress in collaboration with the Medical Research Council on the problems of visual fatigue, attention and adaptation.

\title{
DULWICH COLLEGE EXTENSION TO THE LABORATORIES
}

\section{BY R. GROVES}

\author{
Master of the College
}

$\mathrm{T}$ HERE can be few people now who are not convinced that the British public schools are aware of the country's need of scientific man-power. Not only is the teaching of science in these schools thoroughly 'respectable' now, but also the numbers specializing in science in the sixth forms are often more than 50 per cent of the total numbers in those forms, which is a sign that these schools realize the part that they have to play in meeting the need for scientists. The task now is to give every boy his chance to train as a scientist if he wishes, and this is more onerous than it was, for it means providing not only courses for the pure scientists, but also for those who will become technologists. It must be realized, too, that for every pure scientist we need many technologists, and for every technologist we need an army of technicians : all these have to be trained. Moreover, the sixth forms contain the classics, modern linguists and historians who, though perhaps numerically less, are still happily very strong, and it is to be hopod that they will continue to be so. It is surely essential, however, that an arts boy going up to the university must have some basic grounding in science, for he is going out eventually into a scientific world. Rather than being satisfied with a vague superficial approach to the subject, we have decided that every arts boy at Dulwich College: shall do at least one physical science subject at General Certificate of Education Ordinary Level before going on to specialize in his own subject, thus attempting to give both depth and some idea of scientific method. All these considerations have led us during the past two years to do some hard thinking about the pattern of our scientific teaching, and have inevitably demanded more laboratories.

Perhaps the problem is more acute at Dulwich College, London, in that it is one of the few independent public schools which of its own volition takes a large proportion of its entrants from local authority scholars. This highly competitive entry gives it not only a remarkable cross-section of the population but also some able, fast-moving 'streams' from which many boys will go on to a university to read science or to an advanced technological institution to study applied science of some kind.

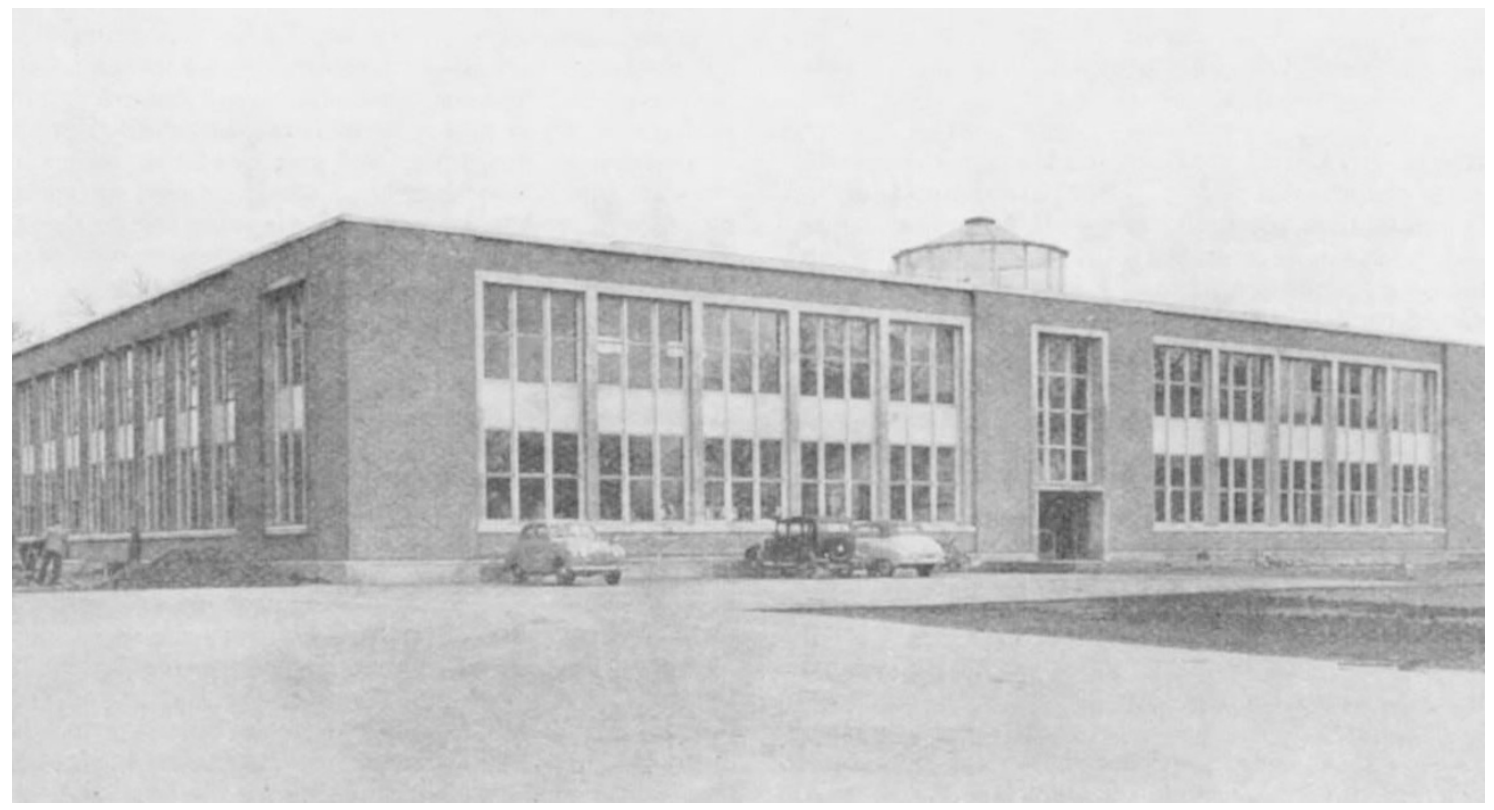

Fig. 1. The Dulwich College Science Block opened in 1952 


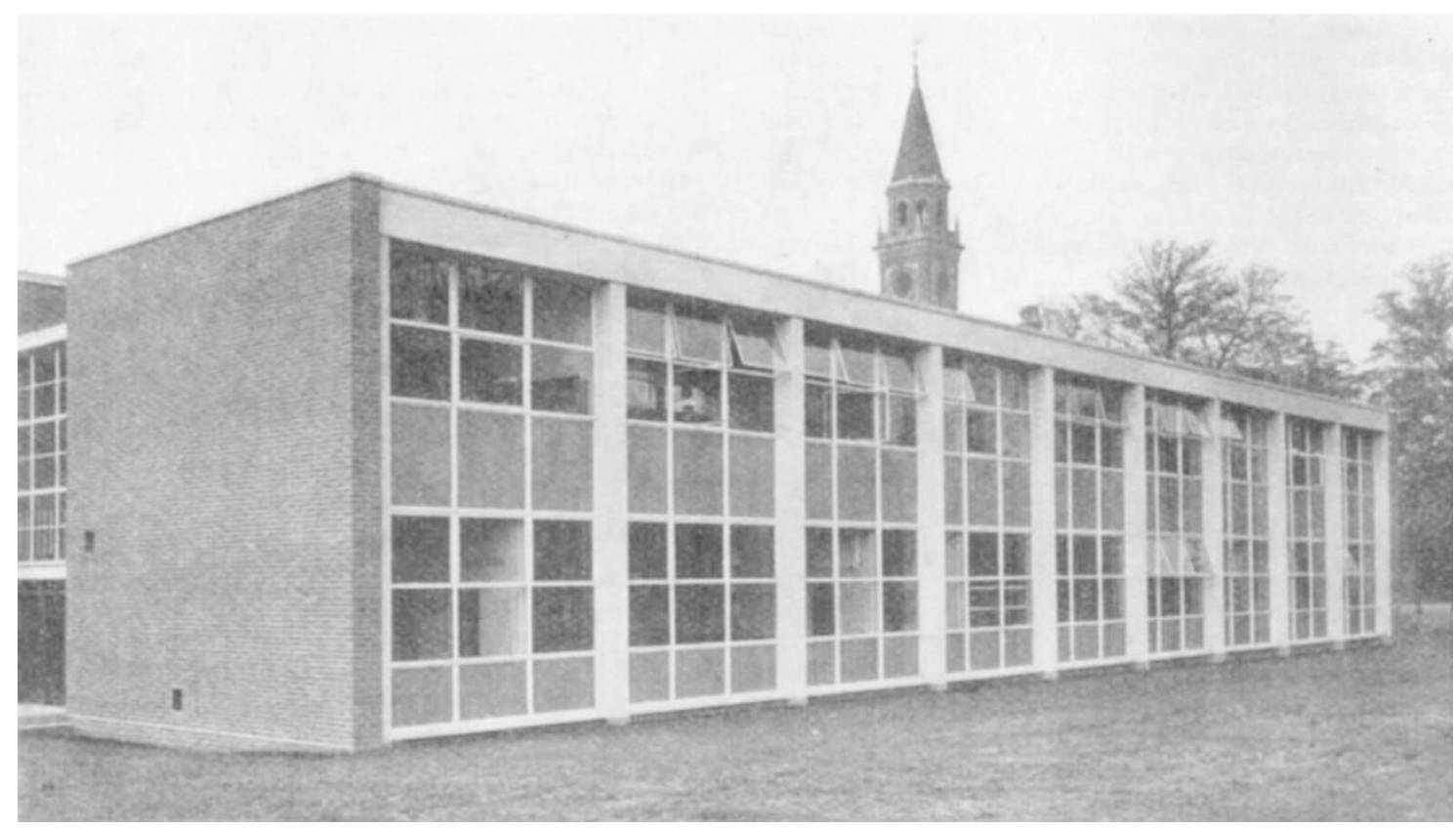

Fig. 2. New extension at the back of the Science Block opened on October 4

[Photo: T. H. Everitt and Som

Historically, the development of this problem is interesting. Science at Dulwich was taught in the early part of the century by H. B. Baker under very primitive conditions, though much of his work on the drying of gases was done here. In 1907 Lord Rayleigh opened a new science block. At that time this must have been one of the best school science buildings in Britain, and even up to the Second World War it compared favourably with many others. It housed chemistry, physics and engineering, for which latter there was a well-equippod woodand metal-work shop; biology was accommodated separately.

In the 1930's the sixth form numbered some 210 , of which perhaps 20 per cent would be scientists. Just before the War this number began to increase, and has continued to do so since the War. The Rayleigh Block was largely destroyed by enemy action in 1944, and teaching had to be done partly in wooden huts and partly in the patched-up building. This continued through the post-war years, until the difficulties of scarcity of materials and money could be overcome, and finally in 1952 a new science block of nine laboratories, two lecture rooms and a library was opened (Fig. 1). This had been planned in 1947 when already some sixty boys were reading science for the General Certificate of Education (Advanced Level); but within a few years of its opening the number had increased to about two hundrod; that is, those sprcializing in science after School Certificate, with one hundred taking the Advanced Level in any one year. This strained the accommodation considerably. The national call for more scientists, the demand within the school, coupled with the generous offer of help from the Industrial Fund for the Advancement of Science in Schools, spurred us on to extend-and to extend quickly. It is expected that with the increase in science teaching generally, by 1960 there will be 250 boys in the school specializing in science after reaching the Ordinary Level of the General Certificate of Education, and for these numbers we had to build our new extension.

This extension, though linked on to the previous block as the fourth long side to complete a quad. rangle, has been built independently so as not to interfere with the working of the original laboratories. It gives five new laboratories, two for advanced and one for elementary chemistry, an advanced physics laboratory with ancillary electrical and dark rooms, together with a junior physics laboratory and a much-needed laboratory workshop. We also have two large lecture rooms which can become one, and thereby accommodate more than two hundred people to take advantage of the modern visual aids. Circulation space has been kept to a minimum, but offices have been provided for the senior chemistry and physics masters, and the usual balance rooms and preparation rooms have been included. Benches have been kept simple, but services to them ample; wooden block floor has been used, though economies have been made everywhere by leaving the brick bare in corridors and keeping decoration very plain. Sixth-form laboratories in particular have very good fume cupboards for chemistry, spaces available for leaving up apparatus when boys are attempting problems of a research nature, and the possibility of research to some extent, both by boys and masters, has been borne in mind in the whole plan.

The project was approved in July 1956, building was started almost immediately, the finished extension was ready for occupation in September 1957, and was officially opened on October 4 (Fig. 2). For this occasion the chairman, Lord Gorell, and the College governors entertained guestis at the College Picture Gallery, at which Sir Harold Hartley, on behalf of the governors, thanked the Industrial Fund for the Advancement of Science in Schools, and $\mathrm{Mr}_{\mathrm{r}}$. John Oriel replied. In the new extension afterwards the Master of the College introduced Sir Cyril Hinshelwood, president of the Royal Society, who addressed the boys and declared the building officially open. 